\title{
Eosinophilic airway inflammation and exacerbations of COPD: a randomised
} controlled trial

\author{
R. Siva, R.H. Green, C.E. Brightling, M. Shelley, B. Hargadon, S. McKenna, \\ W. Monteiro, M. Berry, D. Parker, A.J. Wardlaw and I.D. Pavord
}

ABSTRACT: Evidence suggests that eosinophilic airway inflammation is important in the pathogenesis of severe chronic obstructive pulmonary disease (COPD) exacerbations. The present authors tested the hypothesis that a management strategy that aims to reduce sputum eosinophil counts is associated with a reduction in exacerbations of COPD.

A total of 82 patients with COPD were randomised into two groups. One group was treated according to traditional guidelines (British Thoracic Society (BTS) group) and the other (sputum group) was treated with the additional aim of minimising eosinophilic airway inflammation, assessed using the induced sputum eosinophil count. The primary outcome was exacerbations, which were categorised as mild, moderate or severe.

The frequency of severe exacerbations per patient per year was 0.5 and 0.2 in the BTS and sputum groups, respectively (mean reduction $62 \%$ ). The majority of this benefit was confined to patients with eosinophilic airway inflammation. There was no difference in the frequency of mild and moderate exacerbations. The average daily dose of inhaled or oral corticosteroids during the trial did not differ between the groups. Out of 42 patients in the sputum group, 17 required regular oral corticosteroids to minimise eosinophilic airway inflammation.

A management strategy that aims to minimise eosinophilic airway inflammation, as well as symptoms, is associated with a reduction in severe exacerbations of chronic obstructive pulmonary disease.

KEYWORDS: Airway inflammation, chronic obstructive pulmonary disease, corticosteroids, eosinophils, exacerbations

hronic obstructive pulmonary disease (COPD) is projected to be the fifth highest cause of morbidity and the third highest cause of mortality worldwide by 2020 [1]. The clinical course of the disease is an accelerated decline in lung function, usually caused by cigarette smoking, resulting in increasing symptoms and disability, punctuated by exacerbations of the disease. These exacerbations contribute heavily to levels of morbidity and mortality, and are responsible for significant reductions in the quality of life [2]. Whilst milder exacerbations account for a large part of the workload in primary care, it is severe exacerbations, particularly those that result in hospital admissions, which cause most morbidity and mortality. They are also more expensive, costing European hospitals an estimated $€ 3.4$ billion $\cdot \mathrm{yr}^{-1}$ [3]. Exacerbations may be

For editorial comments see page 831 . associated in the increased rate of progression of the disease, since studies show forced expiratory volume in one second (FEV1) does not return to the pre-exacerbation level [4]. Therefore, management strategies that are associated with a reduction in exacerbations of COPD are important, since they are likely to be associated with a reduction in morbidity, mortality, cost and perhaps the rate of progression of the disease. Several therapeutic interventions, including long-acting $\beta$-agonists [5], long-acting anticholinergics [6] and combination inhalers containing long-acting $\beta$-agonists and inhaled corticosteroids [7], have been shown to result in a modest reduction in exacerbation frequency.

Exacerbations are associated with an increase in airway inflammation and a decline in lung
AFFLIATIONS

*Institute for Lung Health, Dept of Respiratory Medicine and Thoracic Surgery, Glenfield Hospital, Leicester, UK.

\section{CORRESPONDENCE}

I.D. Pavord

Institute for Lung Health

Glenfield Hospital

Groby Road

Leicester

LE3 $9 P Q$

UK

Fax: 441162367768

E-mail: ian.pavord@uhl-tr.nhs.uk

Received:

November 082006

Accepted after revision:

January 212007

SUPPORT STATEMENT

The present study was funded out of

departmental research funds.

STATEMENT OF INTEREST

A statement of interest for I.D. Pavord can be found at www.erj.ersjournals. com/misc/statements.shtml

European Respiratory Journal

Print ISSN 0903-1936

Online ISSN 1399-3003 
function. Although traditionally viewed as a neutrophilpredominant inflammatory response, eosinophilic airway inflammation may play a role [8], particularly in more severe COPD exacerbations. During exacerbations, increased numbers of eosinophils have been detected both in induced sputum and in bronchial biopsies [9], whilst blood eosinophilia has been associated with increased mortality in COPD [10]. Furthermore, corticosteroid treatment, which modulates eosinophilic airway inflammation but has a less clear effect on neutrophilic airway inflammation [8], is effective in the treatment [11] and prevention $[12,13]$ of COPD exacerbations. It has already been shown that a management strategy, which had the additional aim of minimising eosinophilic airway inflammation, resulted in a significant reduction in exacerbations and hospitalisations due to asthma [14]. The present authors have also shown that sputum induction is feasible and safe in patients with moderate and severe COPD [15]. This technique was used to test the hypothesis that a management strategy, which has the additional aim of reducing eosinophilic airway inflammation, is associated with a reduction in exacerbations in patients with COPD.

\section{METHOD}

\section{Subjects}

The present authors invited consecutive patients who met the entry criteria at Glenfield hospital (Leicester, UK) between February 2003 and January 2004 to participate in the study. The diagnosis of COPD was based on a compatible history and spirometry (Vitalograph, Maids Moreton, UK), showing a postbronchodilator FEV1/forced vital capacity ratio of $<70 \%$ and FEV1 $<80 \%$ predicted. All patients had fixed airway obstruction, as suggested by an FEV1 increase of $<15 \%$ from prebronchodilator baseline, or if FEV1 is $<1.2 \mathrm{~L},<200 \mathrm{~mL}$ increase $15 \mathrm{~min}$ after the administration of $400 \mu \mathrm{g}$ inhaled salbutamol via a large volume spacer. Exclusion criteria were: 1) patients $<45$ yrs old; 2) a clinical history of asthma or acute wheeze, breathlessness or deterioration associated with allergens; and 3) clinically important and objectively demonstrated comorbidity, such as heart failure, bronchiectasis or lung cancer. The study was approved by the local research ethics committee and all patients gave written informed consent.

\section{Measurements}

The following baseline characteristics were recorded: age; sex; detailed smoking history; pulmonary rehabilitation status; body mass index; serum immunoglobulin $\mathrm{E} ; \alpha_{1}$-antitrypsin level; and blood eosinophil count. The use of corticosteroids or antibiotics and the number of hospitalisations due to COPD in the previous year, validated by case note review, were also recorded. Patients then underwent a chest radiograph and measurement of exhaled nitric oxide (NO), calculated from the best of three attempts at an exhalation flow rate of $250 \mathrm{~mL} \cdot \mathrm{s}^{-1}$ with a chemiluminescence analyser (Logan Research, Rochester, UK). Full pulmonary function tests were performed on all patients. Spirometry was performed using a Vitalograph ${ }_{\circledR}$ and taking the best of three readings. Gas transfer and total lung volumes were measured using the single breath-hold carbon monoxide and helium dilution techniques, respectively. Sputum induction was performed according to a standard protocol $[15,16]$. Patients completed symptom diary cards and recorded morning peak flow everyday. Short-acting $\beta$-agonists or anticholinergics and long-acting bronchodilators were withheld for 6 and $12 \mathrm{~h}$, respectively, prior to each visit. At each visit patients underwent NO measurement, spirometry before and $15 \mathrm{~min}$ after administration of $400 \mu \mathrm{g}$ inhaled salbutamol via a large volume spacer device and sputum induction. Quality of life was also assessed using the Chronic Respiratory Questionnaire [17]. Patients symptoms were assessed with the aid of visual analogue scales (VAS). At each visit patients marked three lines each measuring $100 \mathrm{~mm}$, which represented the symptoms of breathlessness, cough and sputum production. A significant change in symptoms was assumed and, therefore, there was a need to step-up or step-down treatment if the total VAS score differed by $>34 \mathrm{~mm}$ from the score on the baseline visit, since this is $>2 \times \mathrm{SD}$ outside the limits of repeatability of this measure in patients with COPD [15].

\section{Protocol}

In order to ensure optimal matching of groups, the process of minimisation [18] was used by a third party to randomise subjects into two groups. Stratification of patients was performed according to FEV1, baseline sputum eosinophil count and hospital admission for COPD in the previous year. Patients were followed-up monthly for the first 6 months, then every 2 months for the next 6 months. One group was treated according to a protocol designed to optimise symptoms (British Thoracic Society (BTS) management group) and the other according to a protocol designed to minimise eosinophilic airway inflammation, as well as optimising symptoms (sputum management group; table 1).

\section{TABLE 1 Treatment algorithm}

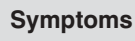

$<1 \%$
Sputum eosinophils

\section{$>3 \%$}

Decrease bronchodilator

No change in anti-inflammatory

No change in bronchodilator

No change in anti-inflammatory

Increase bronchodilator
No change in anti-inflammatory
Decrease bronchodilator Increase anti-inflammatory No change in bronchodilator Increase anti-inflammatory Increase bronchodilator Increase anti-inflammatory 


\begin{tabular}{lr}
\hline TABLE 2 & $\begin{array}{l}\text { Hierarchy of bronchodilator and anti- } \\
\text { inflammatory treatment }\end{array}$ \\
\hline Bronchodilator & Anti-inflammatory \\
\hline No treatment & No treatment \\
Short-acting $\beta$-agonist, as required & ICS $<400 \mu \mathrm{g}$ \\
Regular short-acting anticholinergic & ICS $<800 \mu \mathrm{g}$ \\
Long-acting $\beta$-agonist & ICS $<2000 \mu \mathrm{g}$ \\
Long-acting anticholinergic & Prednisolone $5 \mathrm{mg}$ daily \\
Theophylline & Prednisolone $10 \mathrm{mg}$ daily \\
Nebuliser trial & Prednisolone $30 \mathrm{mg}$ daily \\
\hline ICS: inhaled corticosteroids. ICS doses are beclomethasone equivalents·day ${ }^{-1}$.
\end{tabular}

Patients in both groups were informed of changes to treatment by telephone within 5 days of the previous visit. For the BTS management group, the hierarchy of treatment was: shortacting $\beta$-agonist, regular anticholinergic, long-acting $\beta$-agonist, long-acting anticholinergic, theophylline and, finally, a trial with a nebuliser (table 2). In this group, inhaled corticosteroids were continued at the same dose if patients were already receiving them. In other patients, inhaled corticosteroids $(800-$ $1,000 \mu \mathrm{g}$ beclomethasone equivalents $\cdot$ day $^{-1}$ ) were commenced at visit one if there was a $>15 \%$ improvement in FEV1, or $200 \mathrm{~mL}$ following a 2-week course of $30 \mathrm{mg}$ of prednisolone, as recommended by guidelines at the time [19]. For the sputum management group, patients followed the same hierarchy for symptom control as described previously, but also followed an additional protocol designed to minimise the sputum eosinophil count by using the smallest appropriate dose of antiinflammatory treatment. The aim was to keep the sputum eosinophil count at $<3 \%$, as there is little evidence of the benefit of corticosteroids below this level $[8,20]$. Where the sputum eosinophil count was $>3 \%$, anti-inflammatory treatment was increased. The increased dosing of inhaled corticosteroids was just a doubling-up of dose in line with common clinical practice. Where the count was $1-3 \%$, anti-inflammatory treatment was not changed and, where the count was $<1 \%$, anti-inflammatory treatment was reduced. Treatment was not stepped down if a severe exacerbation, as defined hereafter, had occurred in the previous month irrespective of symptoms. The hierarchy for anti-inflammatory treatment is shown in table 2 .

When the patient could not produce an adequate sputum sample, the NO concentration in exhaled air was used as a surrogate marker of eosinophilc airway inflammation. The aim was to achieve a NO level 3-8 ppb, based on levels of NO in patients with stable and unstable COPD [21] and to be consistent with the present authors' earlier work in asthma [14], using the same anti-inflammatory hierarchy of medication. Bias was avoided by ensuring that the investigators responsible for identifying exacerbations and determining clinical control, as well as the clinician responsible for changing treatment, were not aware of the randomisation status of the patients.

For the present study the definition of an exacerbation of COPD was "a sustained worsening of the patients' condition from the stable state, beyond normal day-to-day variations, that is acute in onset and necessitates a change in regular medication in a patient with underlying COPD". Exacerbations were recorded as mild, moderate or severe [13] as follows. 1) Mild: confirmed in the diary card by a change in major and/or minor symptoms characterised by either two or more of three major symptoms (i.e. increasing breathlessness, sputum volume or sputum purulence), or any one major symptom together with any two minor symptoms (i.e. increase in nasal discharge, wheeze, sore throat, cough or fever) for $\geqslant 2$ days consecutively but successfully self-managed at home. 2) Moderate: worsening of respiratory symptoms resulting in the patient being treated by a family doctor or making an unscheduled attendance to clinic. 3) Severe: worsening of respiratory symptoms resulting in the patient being admitted to hospital.

\section{Analysis}

The primary end-points were mild, moderate and severe exacerbations of COPD, as defined previously. Secondary endpoints were: 1) mean daily use of inhaled and oral corticosteroids; 2) change in lung function; 3) symptom VAS; and 4) quality-of-life scores. The demographics of the two groups were compared using simple descriptive statistics. Mean sputum eosinophil counts for 12 months, expressed as total area under the curve, were compared using unpaired t-tests. The frequency of severe exacerbations was analysed using Poisson regression with adjustment for the slight difference in baseline frequency of severe exacerbations in the previous year. The frequency of mild and moderate exacerbations did not fit a Poisson distribution and were instead compared using negative binomial regression. Change in FEV1, symptoms, quality of life and total oral and inhaled corticosteroid usage was analysed by repeated ANOVA. Doses of inhaled corticosteroids have been expressed as beclamethasone dose equivalents, with fluticasone considered to be twice as potent and budesonide equipotent. The study was powered to have a $>80 \%$ chance at the $5 \%$ level of detecting a $25 \%$ and a $66 \%$ reduction in moderate and severe exacerbations, respectively, based on an estimated exacerbation frequency (mean $\pm \mathrm{SD}$ ) of $1.9 \pm 2.6 \cdot$ patient $^{-1} \cdot \mathrm{yr}^{-1}$ according to the Inhaled Steroids in Obstructive Lung Disease in Europe study [12] and the present study's audit data, which shows an estimated severe exacerbation frequency of $0.6 \cdot$ patient $^{-1} \cdot \mathrm{yr}^{-1}$. Data from patients who did not complete the study was analysed by intention-to-treat and extrapolated for the 12-month period.

\section{RESULTS}

A total of 112 patients were approached, of whom 90 agreed to participate in the study. The majority of patients who declined study entry did so for logistical reasons. Prior to randomisation, four patients withdrew: three without giving a reason and one as he was started on dialysis. Two patients died: one due to an exacerbation of COPD and the other as a result of myocardial infarction. Two patients were excluded as their lung function did not meet the entry criteria: one showed FEV1 $>80 \%$ pred and the other a significant bronchodilator reversibility. In total, 82 patients were randomised into the two groups (fig. 1). Patients were well matched for baseline characteristics (table 3). 


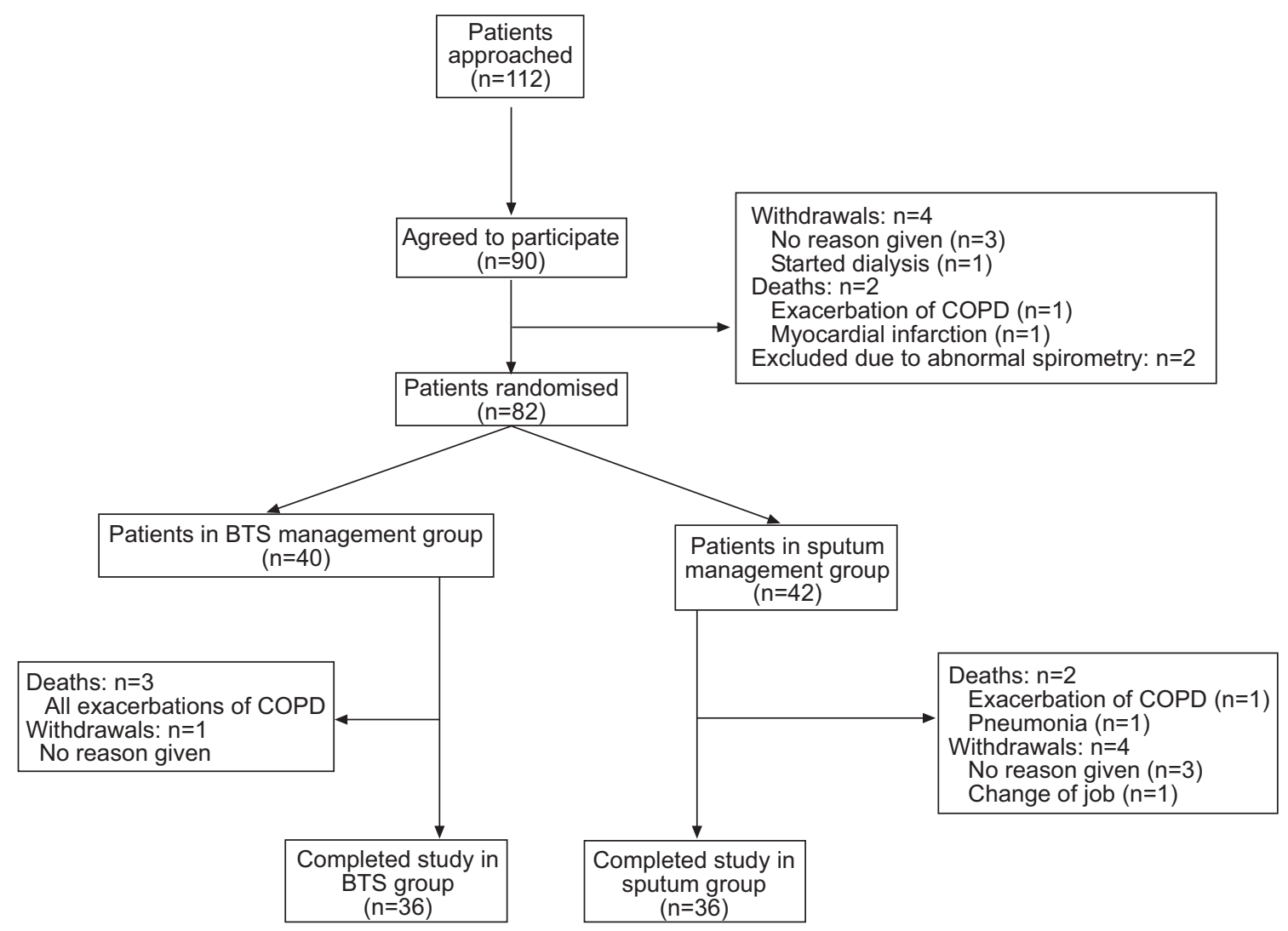

FIGURE 1. Flow chart of the trial profile. COPD: chronic obstructive pulmonary disease; BTS: British Thoracic Society.

Sputum was successfully obtained in 603 out of 746 attempts ( $80.8 \%$ success rate). There were no complications following any of the sputum induction procedures. Overall, the mean sputum eosinophil count, expressed as total area under the curve, was not statistically significantly lower in the sputum management group (mean reduction $(95 \%$ confidence interval (CI) $11(-58-50) \%$; $=0.70)$. However, when each group was stratified according to the baseline sputum eosinophil count, the sputum management was associated with a significant reduction $(63(21-83) \% ; p=0.01)$ in the sputum eosinophil count over 12 months in the subgroup with a baseline eosinophil count of $>3 \%$ (fig. 2).

The total number of severe exacerbations was 20 in nine patients in the BTS group and eight in seven patients in the sputum group. The route of admission was via general practitioner (GP) in 75\% of cases and 999-emergency telephone call in $25 \%$ of cases. The estimated mean $(95 \% \mathrm{CI})$ frequency of severe exacerbations per year was $0.5(0.3-0.8)$ and $0.2(0.1-0.4)$ in the BTS and sputum groups, respectively. There was a significant reduction of $62 \quad(5-72) \%(p=0.037)$ in severe exacerbations between the BTS management group and the sputum management group (fig. 3). Post hoc analysis suggested that most of the benefit occurred in the subgroup who had a baseline sputum eosinophil count of $>3 \%$. In this subgroup, the frequency of severe exacerbations was $0.08 \cdot \mathrm{yr}^{-1}$ in the sputum group $\left(\mathrm{n}=12\right.$, one exacerbation) and $0.7 \cdot \mathrm{yr}^{-1}$ in the control group ( $n=11$, eight exacerbations). The estimated mean frequency of moderate exacerbations was $2.8(2.3-3.4)$ and 2.5 $(2.1-3.1) \cdot \mathrm{yr}^{-1}$ in the BTS and sputum groups, respectively (mean reduction $10(-30-43) \% ; \mathrm{p}=0.66)$. The estimated mean frequency of mild exacerbations was $10.2(9.2-11.2)$ and 7.9 $(7.0-8.8) \cdot \mathrm{yr}^{-1}$ in the BTS and sputum groups, respectively (mean reduction $23(-14-49) \% ; \mathrm{p}=0.22)$.

Overall, there was no difference in the use of oral corticosteroids between the two groups. The mean \pm SD dose patient $^{-1} \cdot$ day $^{-1}$ of oral prednisolone was $1.9 \pm 0.9 \mathrm{mg}$ in the BTS group compared with $2.0 \pm 0.6 \mathrm{mg}$ in the sputum group $(p=0.22)$. All oral corticosteroid use in the BTS group was due to short courses of predinisolone in response to exacerbations. The mean \pm SD dose of inhaled corticosteroid (beclomethasone equivalent dose. patient ${ }^{-1} \cdot$ day $^{-1}$ ) was $1,248 \pm 25 \mu \mathrm{g}$ in the BTS group compared with $976 \pm 51 \mu \mathrm{g}$ in the sputum group. Although less inhaled corticosteroid was used in the sputum group throughout the study $(p=0.001)$, the mean change in daily dose of inhaled corticosteroid between the two groups from baseline did not differ $(p=0.22)$. A total of 35 of the 40 patients in the BTS group were taking inhaled corticosteroids. Out of the 42 patients in the sputum management group, 17 required oral corticosteroids to reduce sputum eosinophils at some stage and 11 finished the study on less inhaled corticosteroid than they had started with. Out of these 11 patients, five individuals were completely weaned off inhaled corticosteroids. There was no significant change in post-bronchodilator FEV1, quality of life or symptoms between the two groups (fig. 4). In a post hoc analysis there was no correlation between baseline exhaled $\mathrm{NO}$ and baseline sputum eosinophil differential cell count in the whole population $(\mathrm{r}=0.174, \mathrm{p}=0.125)$. In order to measure 


\begin{tabular}{|c|c|c|}
\hline & BTS group & Sputum group \\
\hline Subjects $n$ & 40 & 42 \\
\hline Age yrs & $70(49-80)$ & $68(45-82)$ \\
\hline Male/female & $30 / 10$ & $25 / 17$ \\
\hline \multicolumn{3}{|l|}{ Smoking n } \\
\hline Current smoker & 8 & 12 \\
\hline Ex-smoker & 31 & 30 \\
\hline Never-smoker & 1 & 0 \\
\hline Smoking pack-yrs & $47.5 \pm 27.8$ & $50.6 \pm 30.0$ \\
\hline $\mathrm{FEV}_{1} \mathrm{~L}$ & $1.07 \pm 0.44$ & $0.96 \pm 0.47$ \\
\hline FVC L & $2.28 \pm 0.84$ & $2.11 \pm 0.67$ \\
\hline Post-bronchodilator FEV 1 L & $1.14 \pm 0.48$ & $1.04 \pm 0.50$ \\
\hline FEV $1 \%$ pred & $38.4 \pm 15.5$ & $38.1 \pm 15.4$ \\
\hline TLC \% pred & $98.6 \pm 15.3$ & $99.7 \pm 15.4$ \\
\hline RV \% pred & $123.6 \pm 38.1$ & $133.1 \pm 47.1$ \\
\hline KCO \% pred & $75.0 \pm 17.9$ & $65.5 \pm 22.9$ \\
\hline BMI & $26.1 \pm 3.5$ & $26.0 \pm 0.2$ \\
\hline Baseline sputum eosinophil \%\# & $1.5 \pm 0.6$ & $1.7 \pm 0.6$ \\
\hline Blood eosinophils $\times 10^{9} \cdot \mathrm{L}^{-1}$ & $0.24 \pm 0.24$ & $0.20 \pm 0.15$ \\
\hline Exhaled nitric oxide ppb & $5.3 \pm 6.5$ & $7.6 \pm 8.9$ \\
\hline Serum $\lg E^{\#}$ & $61.6 \pm 0.7$ & $36.3 \pm 0.7$ \\
\hline Baseline inhaled steroid dose & $1200 \pm 1007.6$ & $1024 \pm 902.2$ \\
\hline Patients admitted in previous year $n$ & 12 & 12 \\
\hline Rate of admission in previous year & $0.55 \pm 0.7$ & $0.43 \pm 0.6$ \\
\hline Attended pulmonary rehab within $1-y r$ prior to study $n$ & 10 & 9 \\
\hline
\end{tabular}

the success of the blinding procedures, patients were asked to guess which group they thought they had been allocated to; 28 patients guessed correctly, 28 patients guessed incorrectly and 16 patients were unsure.

\section{DISCUSSION}

It has been shown that a management strategy that aims to minimise eosinophilic airway inflammation and symptoms is associated with a significant reduction in the frequency of COPD exacerbations requiring hospital admission. The majority of this benefit occurred in patients with significant eosinophilic airway inflammation. The management strategy was associated with no overall increase in the use of inhaled or oral corticosteroids, although there was evidence that increased corticosteroid therapy was targeted to patients with eosinophilic airway inflammation in the intervention group. No difference was observed in the frequency of mild, selfmanaged exacerbations or in the frequency of moderate exacerbations requiring GP or unscheduled clinic review.

The present findings suggest an association between eosinophilic airway inflammation and severe exacerbations of COPD. This interpretation is consistent with earlier work identifying increased eosinophilic airway inflammation at the time of a COPD exacerbation [9] and epidemiological evidence of an association between the peripheral blood eosinophil count and death from exacerbations of COPD [10]. Corticosteroid therapy appears to have a selective inhibitory effect on eosinophilic airway inflammation in COPD [8, 22]. Further support for a role of eosinophilic airway inflammation in the genesis of exacerbations of COPD is provided by consistent evidence that corticosteroid treatment increases the rate of recovery from severe exacerbations [11] and prevents the occurrence of severe exacerbations [13]. Whether eosinophilic airway inflammation is causally associated with the exacerbation or indicates the presence of another corticosteroid-responsive mechanism remains unclear. Further studies with a more selective inhibitor of eosinophilic airway inflammation, such as antibodies to anti-interleukin-5 [23], may help answer this question.

The absence of an effect of the management strategy on mild and moderate exacerbations suggests that the mechanism of these events might differ from the mechanism of severe exacerbations of COPD. There is some support for this view, since treatment with inhaled fluticasone is associated with a greater reduction in severe exacerbations of COPD than less severe events [13]. Inhaled corticosteroid therapy is also more effective in patients with more severe airflow obstruction [24] and it remains possible that the underlying pathology and corticosteroid responsiveness of COPD exacerbations differ with increasing disease severity. Future studies should investigate this possibility. 

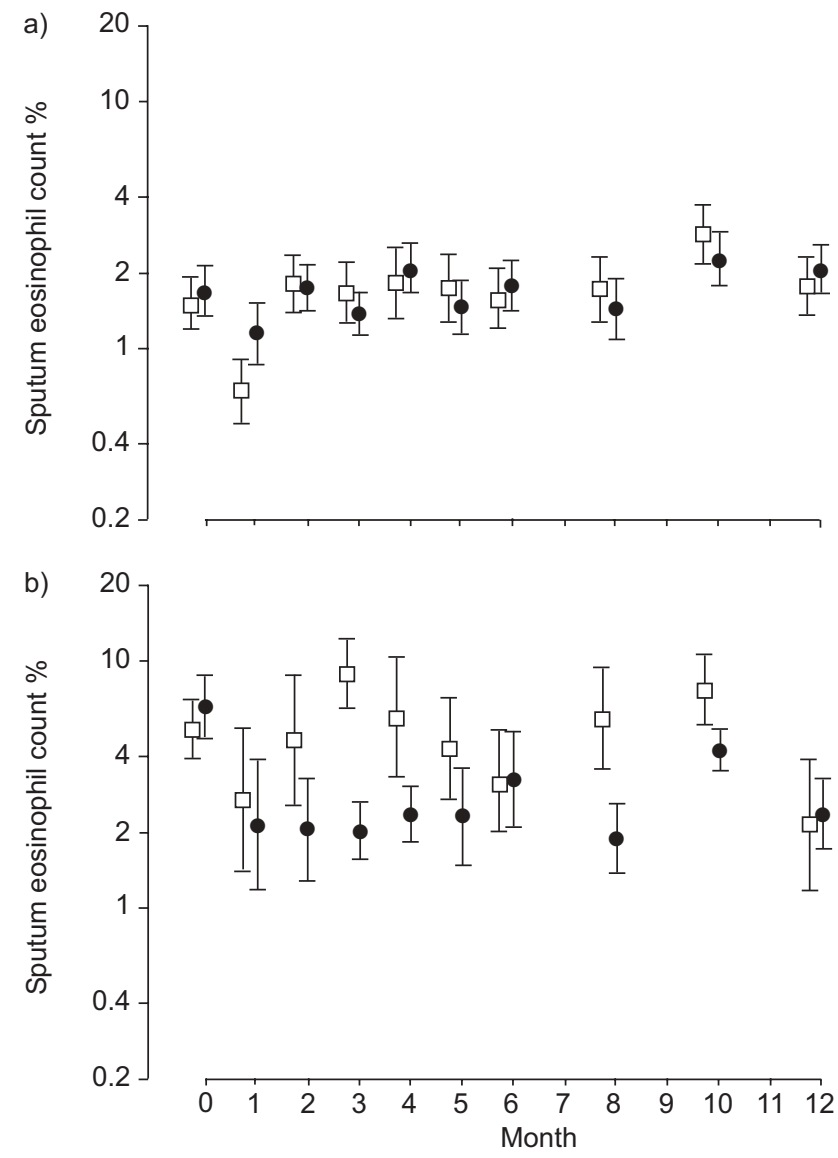

FIGURE 2. Sputum eosinophil counts per month for a) all patients and b) patients with baseline sputum eosinophil count $>3 \%$. The whiskers represent SEM. $\square$ : British Thoracic Society group; : sputum group.

There are parallels between the present findings in patients with predominantly severe COPD and earlier findings in a study of patients with severe asthma [14], where a similar management strategy was associated with a $68 \%$ reduction in severe exacerbations and a marked reduction in the number of exacerbations requiring hospital admissions. This suggests that there might be similarities in the mechanism of exacerbations of COPD and severe asthma. However, one important difference in the findings of both studies is that there was a less striking reduction in the sputum eosinophil count in the intervention group in patients with COPD than there was in patients with asthma. This is likely to be because a sputum eosinophilia was a less consistent feature in patients with COPD than in asthma. Another possibility is that COPD is associated with a degree of inhaled corticosteroid resistance, perhaps because the functionally important eosinophilic airway inflammation is confined to the distal airways [25, 26]. It is notable that when the analysis was confined to the group of patients with the highest baseline sputum eosinophil counts, a significant decrease was observed in the sputum eosinophil count over the 12 months of the study and much of the benefit was confined to this subgroup. Interestingly, it was often necessary to use long-term oral corticosteroid therapy to achieve this.

Another potential limitation of the present study is that sputum differential cell counts were not available for $\sim 20 \%$

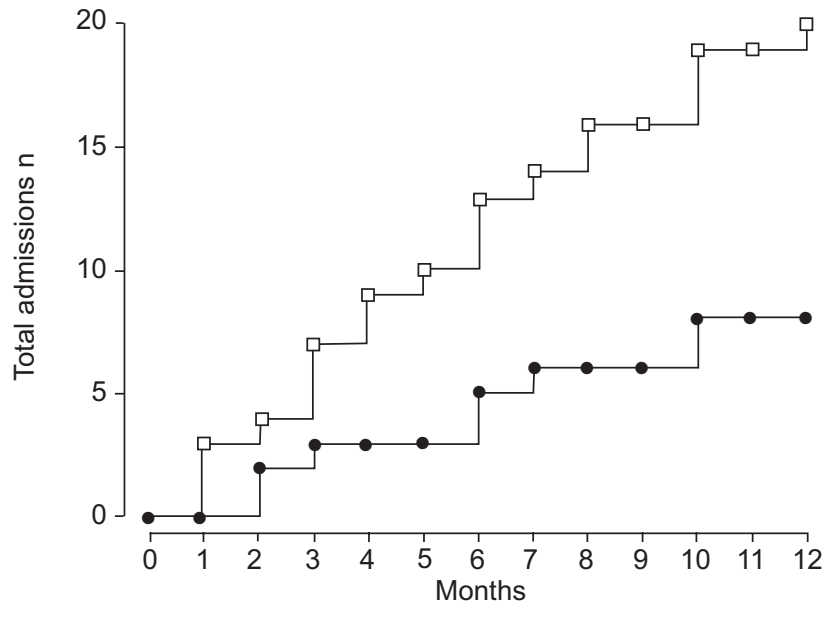

FIGURE 3. Hospital admissions in the British Thoracic Society ( $\square$ ) and sputum (•) groups. $p=0.037$.

of visits. Exhaled $\mathrm{NO}$ was elected as a surrogate marker of eosinophilic airway inflammation. NO is an imperfect marker of eosinophilic airway inflammation, particularly in current smokers [21]. However, the present approach is supported by some evidence that exhaled NO correlates with sputum eosinophil counts in COPD [27] and that a raised exhaled $\mathrm{NO}$ is more closely related to a positive response to corticosteroid therapy than other clinical markers in patients with airways disease in general [28]. No significant relationship was found between baseline exhaled NO and baseline sputum eosinophil counts. This suggests that exhaled NO is not a good marker for titrating steroid therapy in COPD. Despite this, the present authors were still able to demonstrate a significant effect with the current management strategy. The fact that sputum eosinophil counts were not available in a significant number of patients and the absence of a wellvalidated alternative marker are significant problems with the use of inflammatory markers in the management of COPD.

It was not possible to conduct the study in a truly double-blind fashion. However, extra care was taken to ensure that the clinician making decisions about clinical control was blind to the patients' randomisation status and that management decisions were protocol driven. Furthermore, decisions about hospitalisation and management of exacerbations were largely taken by the patient or their primary-care physician, who were both blind to the randomisation status. The present authors' decisions about clinical control were based upon the patients' response to a previously validated symptom VAS [17]. It is believed that this strategy and the management hierarchy are in keeping with the management strategy advocated by guidelines at the time [19]. However, the possibility that tighter control of symptoms might have been associated with better control of exacerbations cannot be excluded.

The study aim was to investigate the effects of modulation of eosinophilic airway inflammation on outcome in chronic obstructive pulmonary disease. Evaluation of the clinical utility of the management strategy or a cost-benefit analysis have not been undertaken. Although sputum induction 

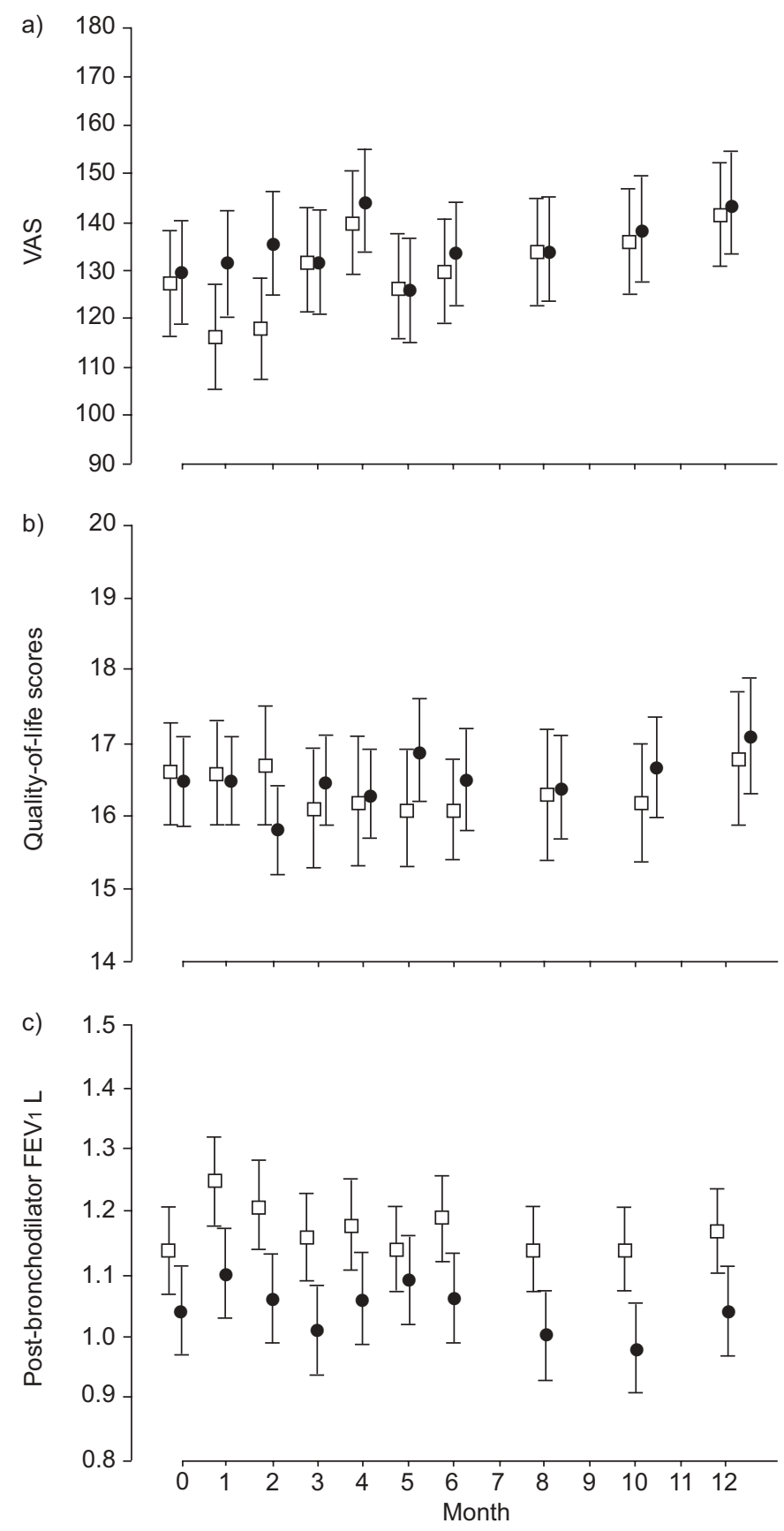

FIGURE 4. a) Symptom scores, b) quality-of-life scores and c) postbronchodilator forced expiratory volume in one second (FEV1) for the British Thoracic Society $(\square)$ and sputum $(\bullet)$ groups. The whiskers represent SEM. VAS: visual analogue scores.

appears to be safe in patients with severe chronic obstructive pulmonary disease [15], processing of induced sputum is a relatively complex procedure associated with significant technician time and expense. The clinical utility of a management strategy incorporating measurements of eosinophilic airway inflammation is likely to be greater if the technique can be simplified and made to provide more immediate results. The present findings should stimulate the development of such techniques.

\section{REFERENCES}

1 Pauwels RA, Buist AS, Calverley PM, Jenkins CR, Hurd SS; Gold Scientific Committee, Global strategy for the diagnosis, management, and prevention of chronic obstructive pulmonary disease. NHLBI/WHO Global Initiative for Chronic Obstructive Lung Disease (GOLD) Workshop summary. Am J Respir Crit Care Med 2001; 163: 1256-1276.

2 Seemungal TA, Donaldson GC, Paul EA, Bestall JC, Jeffries DJ, Wedzicha JA. Effect of exacerbation on quality of life in patients with chronic obstructive pulmonary disease. Am J Respir Crit Care Med 1998; 157: 1418-1422.

3 European Respiratory Society/European Lung Foundation. Preliminary data from the European Lung White Book on lung disease, 2002. www.ersnet.org. Date last accessed: February 5, 2007.

4 Donaldson GC, Seemungal TA, Bhowmik A, Wedzicha JA. Relationship between exacerbation frequency and lung function decline in chronic obstructive pulmonary disease. Thorax 2002; 57: 847-852.

5 Mahler DA, Donohue JF, Barbee RA, et al. Efficacy of salmeterol xinafoate in the treatment of COPD. Chest 1999; 115: 957-965.

6 Casaburi R, Mahler DA, Jones PW, et al. A long-term evaluation of once-daily inhaled tiotropium in chronic obstructive pulmonary disease. Eur Respir J 2002; 19: 217-224.

7 Calverley P, Pauwels R, Vestbo J, et al. Combined salmeterol and fluticasone in the treatment of chronic obstructive pulmonary disease: a randomised controlled trial. Lancet 2003; 361: 449-456.

8 Brightling CE, Monteiro W, Ward R, et al. Sputum eosinophilia and short-term response to prednisolone in chronic obstructive pulmonary disease: a randomised controlled trial. Lancet 2000; 356: 1480-1485.

9 Saetta M, Stefano AD, Maestrelli P, et al. Airway eosinophilia in chronic bronchitis during exacerbations. Am J Respir Crit Care Med 1994; 150: 1646-1652.

10 Hospers JJ, Schouten JP, Weiss ST, Rijcken B, Postma DS. Asthma attacks with eosinophilia predict mortality from chronic obstructive pulmonary disease in a general population sample. Am J Respir Crit Care Med 1999; 160: 1869-1874.

11 Davies L, Angus RM, Calverley PM. Oral corticosteroids in patients admitted to hospital with exacerbations of chronic obstructive pulmonary disease: a prospective randomised controlled trial. Lancet 1999; 354: 456-460.

12 Burge PS, Calverley PM, Jones PW, Spencer S, Anderson JA, Maslen TK. Randomised, double blind, placebo controlled study of fluticasone propionate in patients with moderate to severe chronic obstructive pulmonary disease: the ISOLDE trial. BMJ 2000; 320: 1297-1303.

13 Paggiaro PL, Dahle R, Bakran I, Frith L, Hollingworth K, Efthimiou J. Multicentre randomised placebo-controlled trial of inhaled fluticasone propionate in patients with chronic obstructive pulmonary disease. International COPD Study Group. Lancet 1998; 351: 773-780.

14 Green RH, Brightling CE, McKenna S, et al. Asthma exacerbations and sputum eosinophil counts: a randomised controlled trial. Lancet 2002; 360: 1715-1721.

15 Brightling CE, Monterio W, Green RH, et al. Induced sputum and other outcome measures in chronic obstruc- 
tive pulmonary disease: safety and repeatability. Respir Med 2001; 95: 999-1002.

16 Pavord ID, Pizzichini MM, Pizzichini E, Hargreave FE. The use of induced sputum to investigate airway inflammation. Thorax 1997; 52: 498-501.

17 Guyatt GH, Berman LB, Townsend M, Pugsley SO, Chambers LW. A measure of quality of life for clinical trials in chronic lung disease. Thorax 1987; 42: 773-778.

18 Treasure T, MacRae KD. Minimisation: the platinum standard for trials? Randomisation doesn't guarantee similarity of groups; minimisation does. BMJ 1998; 317: 362-363.

19 BTS guidelines for the management of chronic obstructive pulmonary disease. The COPD Guidelines Group of the Standards of Care Committee of the BTS. Thorax 1997; 52 Suppl. 5, S1-S28.

20 Pavord ID, Brightling CE, Woltmann G, Wardlaw AJ. Noneosinophilic corticosteroid unresponsive asthma. Lancet 1999; 353: 2213-2214.

21 Maziak W, Loukides S, Culpitt S, Sullivan P, Kharitonov SA, Barnes PJ. Exhaled nitric oxide in chronic obstructive pulmonary disease. Am J Respir Crit Care Med 1998; 157: 998-1002.

22 Brightling CE, McKenna S, Hargadon B, et al. Sputum eosinophilia and the short term response to inhaled mometasone in chronic obstructive pulmonary disease. Thorax 2005; 60: 193-198.

23 Leckie MJ, ten Brinke A, Khan J, et al. Effects of an interleukin-5 blocking monoclonal antibody on eosinophils, airway hyper-responsiveness, and the late asthmatic response. Lancet 2000; 356: 2144-2148.

24 Jones PW, Willits LR, Burge PS, Calverley PM. Disease severity and the effect of fluticasone propionate on chronic obstructive pulmonary disease exacerbations. Eur Respir J 2003; 21: 68-73.

25 Hogg JC, Chu F, Utokaparch S, et al. The nature of smallairway obstruction in chronic obstructive pulmonary disease. N Engl J Med 2004; 350: 2645-2653.

26 Berry M, Hargadon B, Morgan A, et al. Alveolar nitric oxide in adults with asthma: evidence of distal lung inflammation in refractory asthma. Eur Respir J 2005; 25: 986-991.

27 Rutgers SR, van der Mark TW, Coers W, et al. Markers of nitric oxide metabolism in sputum and exhaled air are not increased in chronic obstructive pulmonary disease. Thorax 1999; 54: 576-580.

28 Smith $\mathrm{AD}$, Cowan JO, Brassett KP, et al. Exhaled nitric oxide: a predictor of steroid response. Am J Respir Crit Care Med 2005; 172: 453-459. 